\title{
Practical Aspects of the Electron Probe Analysis of Boron in Silicates using a LSM Device with Large 2d
}

\author{
George B Morgan VI
}

\section{Electron Microprobe Laboratory, University of Oklahoma, Norman, USA}

The development of Layered Synthetic Microstructures (LSM; also called Layered Dispersion Elements-LDE and, inaccurately, PseudoCrystals-PC) through the 1980's provided electron probe analysts using wavelength-dispersive spectrometry (WDS) access to the K-alpha emissions of the ultralight elements down at least to boron $(\mathrm{Z}=5)$ in the periodic table[1]. Although quite a bit has been reported subsequently about analytical methods for boron[2], little discussion has been directed at optimizing analysis on the basis of the type of diffraction element used or the effect of matrix type on the intensity and shape of the background (Bremsstrahlung) surrounding $\mathrm{B} \mathrm{K \alpha}$ in silicate or borate materials. Regardless of the type of diffraction device, the B K $\alpha$ peak is very broad and measuring its intensity from most silicate and borate matrices is complicated by sharply increasing background intensity on the high-energy side of the peak (HEB: High-Energy Background) (Figure 1). Using an LSM with $2 d$ in the range of $\sim 147-200 \AA$, diffraction of B K $\alpha$ occurs at $2 \theta<<45^{\circ}\left(\sim 27.4-19.8^{\circ}\right)$ and so removes most of the polarization-induced changes in peak shape as a function of orientation from crystalline materials with symmetries between those of the cubic and triclinic systems. The original LSMs with 2d in the 145-200Á range are Mo- $\mathrm{B}_{4} \mathrm{C}$ interlayer devices. The first principal task of analysis with these devices is choosing a peak position and background offsets (or single offset and slope) that minimize or eliminate intensity from internal fluorescence of the $\mathrm{B}_{4} \mathrm{C}$ interlayers (Figure 1). Pulse height analysis methods need to utilize the Differential Mode in order to eliminate high-order diffractions of higher-energy x-ray emissions that, although reputedly are eliminated by LSMs, occur both under the B K $\alpha$ peak and in the HEB.

Differences in absorption and background intensity, slope, and shape make boron metal and simple boride compounds poor choices as standards for analyzing silicate or borate materials. WDS scanning of a variety of silicate materials demonstrates that the intensity and slope of the background around the B $\mathrm{K} \alpha$ peak changes with increasing average atomic number $\left(Z_{\mathrm{Avg}}\right)$ and density $(\rho)$ of the sample, making the match between standard and sample important. Among silicates, the background slope decreases with increasing $Z_{\text {Avg }}$ and $\rho$ such that significant intensity from internal fluorescence is counted in Ferich, high-Z materials; this yields significant fictive boron unless the offset on the HEB is widened (or the background slope is modeled appropriately) relative to methods appropriate for materials with lower $\mathrm{Z}_{\text {Avg. }}$. The analysis of crystals is made more straightforward by using crystalline primary standards that match the chemistry and coordination environments for boron in the unknowns as closely as possible. Average $\mathrm{Z}$ and density effects also lead to an increase in background intensity and slope for glasses relative to crystalline materials such that the use of a glassy primary standard for analyzing minerals may lead to fictive positive boron contents. Conversely, the use of crystalline standards for glass analysis can lead to inaccurately low results for boron that can include negative net peak intensity at zero concentration. The best approach for glass analysis is to use a high-boron $\left(\geq 10 \mathrm{wt} \% \mathrm{~B}_{2} \mathrm{O}_{3}\right)$ silicate glass as the primary standard, and then two or more secondary standards - one with nil and another with intermediate boron content - to evaluate accuracy over a range of concentration down to the detection limit. Moreover, using an anhydrous glass standard for boron, the analysis of a pair of initially identical anhydrous and hydrated B-free glasses produced 0.4-0.6 wt\% fictive $\mathrm{B}_{2} \mathrm{O}_{3}$ in the hydrated glass that is 
not seen in the anhydrous glass, perhaps due to a decrease in background intensity accompanying lowered $\mathrm{Z}$ and $\rho$, and/or increased adsorption by higher oxygen content.

With the above concerns taken into account, routine analysis of boron in silicates easily obtain minimum detection limits in the $0.2-0.3 \mathrm{wt} \% \mathrm{~B}_{2} \mathrm{O}_{3}$ range with 30-60 second count times using $15 \mathrm{kV}$ acceleration (and lower concentration at lower accelerating voltage). Such limits, however, depend strongly on the thickness of the entrance window to the proportional counter. Polymer support grids or inadequately stretched polypropylene can reduce intensity of the B K $\alpha$ peak by as much as $70 \%$, thereby increasing the minimum detectable concentration.

[1] G.F. Bastin and H.J.M Heijligers, in “Electron Probe Quantitation”, ed. K.F.J Heinrich and D.E. Newbury, (Plenum, New York), p. 145-175.

[2] J.J. McGee and L.M. Anovitz, in “Boron Mineralogy, Petrology and Geochemistry”, ed. E.S. Grew and L.M. Anovitz, (Mineralogical Society of America, Washington D.C.), p. 771-788.

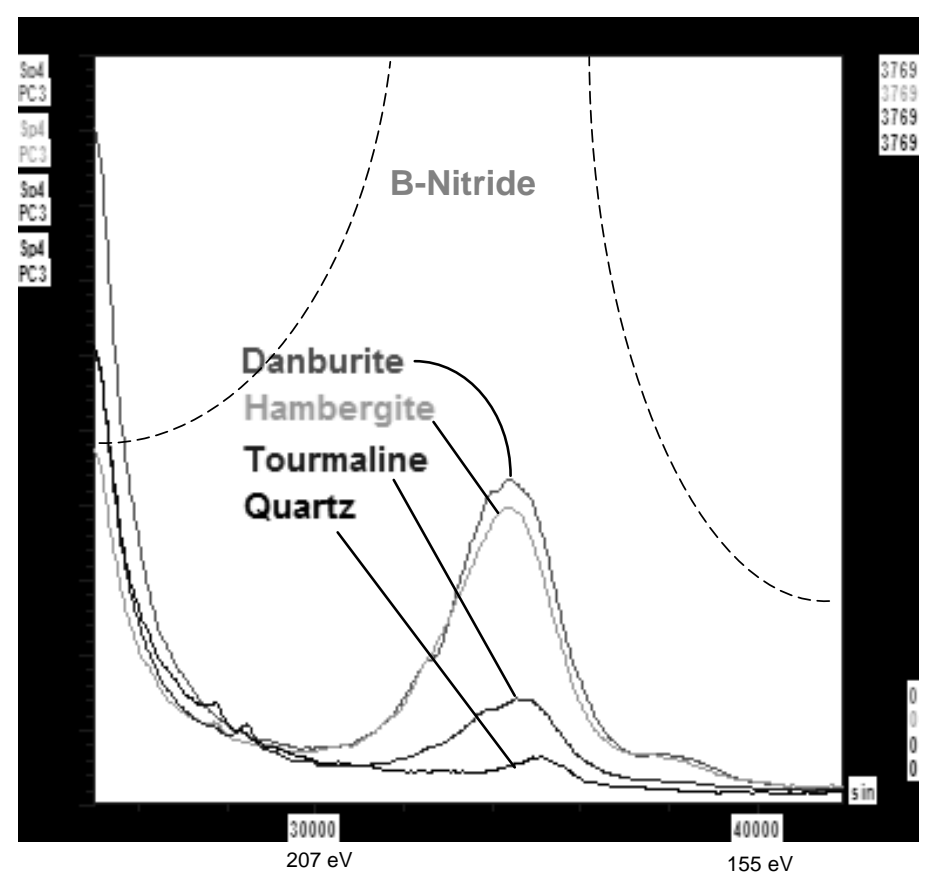

Figure 1. Wavelength-dispersive spectrometer scans (15 kV, $100 \mathrm{nA})$ across $\mathrm{B} \mathrm{K} \alpha$ region using LSM with 2d 200Á on quartz $\left(\mathrm{SiO}_{2}\right)$, tourmaline $\left[\left(\mathrm{Na}_{0.6} \mathrm{Ca}_{0.1}\right)\left(\mathrm{Fe}_{1.6} \mathrm{Mg}_{1.2} \mathrm{Al}_{0.2}\right) \mathrm{Al}_{6}\left(\mathrm{BO}_{3}\right)_{3} \mathrm{Si}_{6} \mathrm{O}_{18}(\mathrm{OH})_{4}\right]$, hambergite $\left(\mathrm{Be}_{2} \mathrm{BO}_{3}(\mathrm{OH})\right.$, danburite $\left(\mathrm{CaB}_{2} \mathrm{Si}_{2} \mathrm{O}_{8}\right)$, and boron nitride. Intensity observed on quartz, which is nominally B-free, is due to internal fluorescence within the Mo- $\mathrm{B}_{4} \mathrm{C}$ interlayers of the LSM.

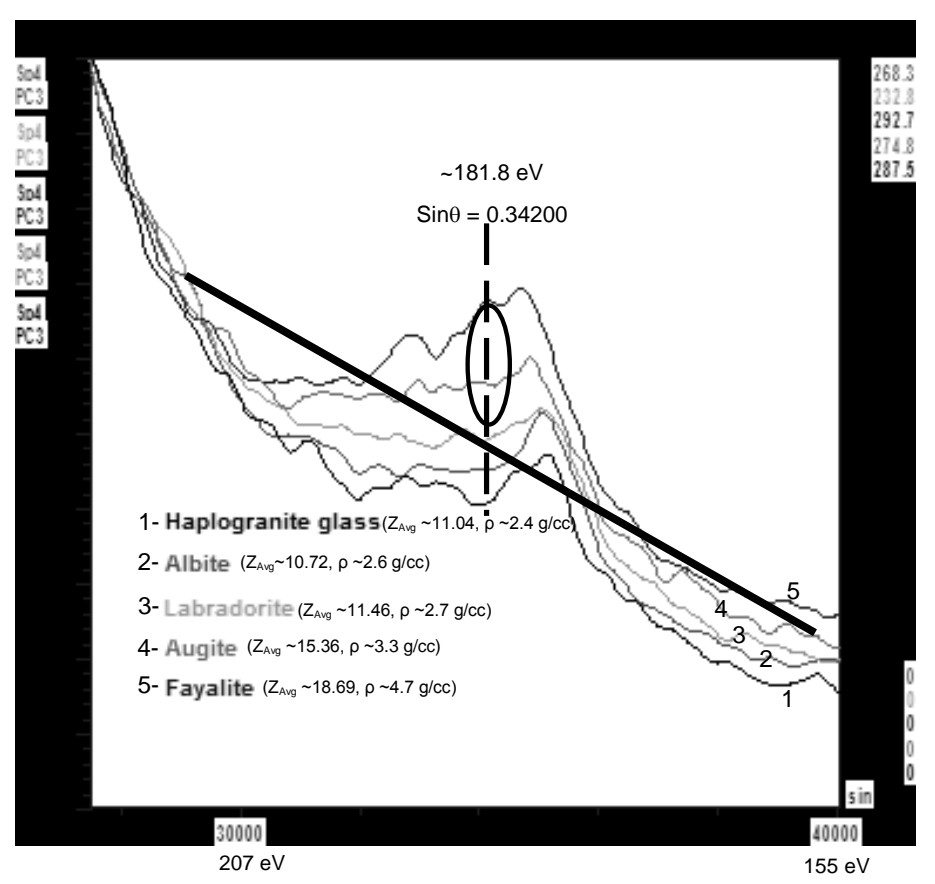

Figure 2. WDS scans showing decrease in the background slope around $\mathrm{B} \mathrm{K} \alpha$ with increasing $\mathrm{Z}_{\mathrm{Avg}}$ and density of the sample. Note that at the chosen peak position (dashed line), the background slope for the default peak offsets used for B-bearing silicates with $\mathrm{Z}_{\mathrm{Avg}} \leq$ 11.6 (heavy line) does not eliminate internal fluorescence from the $\mathrm{B}_{4} \mathrm{C}$ interlayers of the LSM for high-density, Fe-rich silicates (circled). 